\title{
PROCESSO EDUCACIONAL INCLUSIVO: DAS DISCUSSÕES TEÓRICAS À NECESSIDADE DA PRÁTICA
}

\author{
Diego Salomão Candido de O. Salvador \\ Graduando do Curso Superior de Licenciatura em Geografia no CEFET-RN \\ diegolisse@yahoo.com.br \\ Dante Henrique de Moura \\ Doutor em Educação e Professor do CEFET-RN \\ dante@cefetrn.br \\ José Aldivan de A. Silva \\ Graduando do Curso Superior de Licenciatura em Geografia no CEFET-RN \\ tioaldi@yahoo.com.br \\ Silvan Ferreira Maia \\ Graduando do Curso Superior de Licenciatura em Geografia no CEFET-RN \\ silvanmaia@yahoo.com.br
}

\begin{abstract}
RESUMO
O presente artigo trata do processo educacional inclusivo. Nesse processo prevê-se o atendimento educacional significativo a todos, sem exceções, tratando as diferenciações cognitivas, sociais, econômicas, políticas, culturais, dentre outras, como sinônimos de riquezas e não de limitações. Com isso, diz-se que o processo inclusivo é uma opção para dar início à minimização dos graves problemas existentes no sistema educacional em vigência, que é excludente. $\mathrm{O}$ objetivo no artigo é refletir sobre o processo educacional inclusivo. A metodologia adotada é a de revisão bibliográfica de alguns dos pensadores que investigam o tema, bem como com a consideração de percepções de docentes sobre como se apresenta na realidade a inclusão educacional. Por fim, conclui-se que, apesar do modelo social em vigor, algumas mudanças demandadas urgentemente pelos processos educacionais são possíveis, desde que todos os envolvidos no ambiente escolar se comprometam com elas e executem as práticas educacionais inclusivas, que são transformadoras. Para isso, é imprescindível que se leve as premissas da educação inclusiva da teoria à prática.
\end{abstract}

PALAVRAS-CHAVE: Educação. Inclusão. Todos.

\section{PROCESO EDUCACIONAL INCLUSIVO: DE LAS DISCUSIONES TEÓRICAS A LA NECESIDAD DE LA PRACTICA}

\section{RESUMEN}

Este artículo trata del proceso educativo inclusivo. En ese proceso se considera que la educación debe ser proporcionada a todos, sin excepciones, y teniendo en cuenta las diferencias cognitivas, sociales, económicas, políticas, culturales, entre otras, como signos de riquezas en el lugar de considerarlas como obstáculos. Así, el proceso inclusivo es una opción para contribuir con la disminución de los graves problemas existentes en el sistema educativo vigente, lo cual es excluyente. El objetivo del artículo es reflexionar acerca del proceso educativo inclusivo. Se ha adoptado como metodología la revisión bibliográfica de algunos pensadores que estudian el tema y, asimismo, las percepciones de docentes sobre como se presenta la realidad de la inclusión educativa. Al final se ha concluido que es posible lograr algunos de los cambios necesarios a los procesos educativos pese al modelo 
social vigente. Para ello, es fundamental que todos los implicados sepan que es posible implementar practicas educativas inclusivas y transformadoras.

PALABRAS-LLAVE: Educación. Inclusión. Todos. 


\section{PROCESSO EDUCACIONAL INCLUSIVO: DAS DISCUSSÕES TEÓRICAS À NECESSIDADE DA PRÁTICA}

\section{Palavras iniciais}

O presente artigo tem como temática central o processo educacional inclusivo. Nesse processo, prevê-se o atendimento educacional significativo a todos os alunos, sem exceções. Por isso, pode-se declarar que a inclusão educacional é perpassada por características e posturas diferenciadas das que estão em voga no sistema educacional atual.

O objetivo do trabalho é refletir sobre o processo educacional inclusivo. Para isso, este segue estruturado em três partes: na primeira, são realizadas considerações teóricas sobre o processo educacional inclusivo; na segunda, colocam-se em tela reflexões acerca da educação inclusiva no Brasil, quando analisa-se as duas Leis de Diretrizes e Bases da Educação Nacional (Lei no 4.024/1961 e Lei no 9.394/1996); e no terceiro, são trazidas à baila percepções de docentes da rede pública de ensino sobre a educação inclusiva.

\section{Reflexões sobre o processo educacional inclusivo}

Tecer reflexões sobre a educação inclusiva não é tarefa fácil, em função desta apresentar-se como uma questão da contemporaneidade marcada de importância, polêmica e contradição.

A educação inclusiva é importante porque é por meio dela que se pode alcançar significatividade educacional a todos os alunos. É polêmica por que desencadeia diversas e diferentes opiniões sobre como deve ser pensada e praticada. E contraditória porque nos discursos acerca do processo educacional inclusivo ainda há uma grande teia de incoerências e um fosso entre o que se pensa, diz e faz. O meio educacional continua perpassado pelo nós, os ditos normais, e por eles, as pessoas com dificuldades e/ou necessidades especiais (SÁ, 2006).

O processo educacional inclusivo é entendido aqui como aquele em que todos são considerados e atendidos de forma significativa. Nesse processo, as diferenças são tidas como sinônimos de riquezas e não de limitações. Vale ainda frisar que quando se tratar, neste trabalho, de inclusão para alunos com necessidades especiais, se estará pensando de forma bastante ampla, levando em consideração várias dimensões, como a cognitiva, a social, a econômica, a política, a cultural, dentre outras. Dessa forma, não se considera como alunos com necessidades especiais somente àqueles que apresentem deficiências físicas e/ou mentais, mas também aqueles com necessidades sociais, econômicas, culturais etc, os quais também gritam por mudanças educacionais. É por isso que a inclusão escolar é ininterruptamente entendida como aquela que trabalha com absolutamente todos.

Diante desse referencial, é necessário ter claro que uma educação efetivamente inclusiva em toda a sua plenitude é incompatível com o atual modelo de sociedade em que vivemos, na qual as relações sociais, políticas, culturais e econômicas são cada vez mais definidas, quase que exclusivamente, a partir da lógica capitalista. Nessa sociedade, o que deveria ser direito de todos os cidadãos, submete-se à lógica do mercado, e passa a ser um oferecido à 
população sob a forma de prestação de serviços, aos quais só tem acesso quem pode pagar por eles. É assim que avança a privatização de direitos sociais como a saúde, segurança, habitação, educação etc. A partir dessa racionalidade mercantil, a escola nem é para todos nem, tampouco, é igual para os que a ela têm acesso. Existe nos dias atuais a escola básica privada para os que podem pagar e a escola básica pública para os filhos das classes mais populares. Ambas têm como objetivo prioritário atender as premissas do mercado, e não as sociais. A única diferença existente entre a escola privada e a pública é que a primeira atende às premissas mercantis de maneira mais intensa.

Assim sendo, não é possível levar a cabo, em sua plenitude, o conceito de escola inclusiva como sendo aquela à qual todos, independentemente da origem socioeconômica, étnicoracial, religiosa, de gênero ou de qualquer diferença física ou mental, podem ter acesso. A não ser que altere-se o modelo social em que vive-se, partindo-se para um paradigma novo, em que as premissas sociais coletivas sejam colocadas acima das capitalistas individuais.

Feita essa delimitação, pode-se avançar dizendo-se que as discussões sobre o processo educacional inclusivo não são antigas. Durante muito tempo, houve intenso desprezo pelas pessoas que não atendiam aos padrões tradicionais escolares, as quais eram isoladas em hospitais, casas de familiares, clínicas, instituições de ensino especial, dentre outros locais. Foi apenas a partir do século XX, mais precisamente em 1948, que a humanidade acordou e começou a alterar seus preconceitos em relação às pessoas com necessidades educacionais especiais. Nesse ano, foi desenvolvida a primeira diretriz política com a visão de que todos os cidadãos possuem direitos e deveres. Essa diretriz foi pensada na Declaração Universal dos Direitos Humanos, que deixou explícito o direito de todo ser humano a ter educação escolar ${ }^{1}$.

A partir de então, a educação inclusiva passou a ser pensada e discutida em âmbito mundial. $\mathrm{Na}$ atualidade, chega-se a um estágio em que há consideráveis avanços teóricos em relação à questão, não podendo-se dizer o mesmo sobre os avanços práticos. Discute-se muito a educação inclusiva e faz-se muito pouco por ela, sempre utilizando-se da desculpa de que esta não é compatível com o atual modelo político educacional vigente. Todavia, são os homens que constroem esse modelo vigente e, portanto, são eles também que podem construir a realidade educacional inclusiva, até porque essa realidade prevê a participação e a evolução significativa de todos os indivíduos envolvidos no processo educacional. Por isso, é oportuno dizer que quando se trata da educação inclusiva é necessário buscar equilíbrio entre os avanços teóricos e os práticos.

Com estas considerações, partir-se-á agora para discussões acerca do processo educacional inclusivo, calcadas nos seguintes questionamentos: o que é inclusão? Existem diferenças entre inclusão e integração? O que a inclusão escolar provoca? Pode haver progresso educacional por meio da inclusão? Quais as características de uma escola que atende às expectativas inclusivas? Por que a inclusão escolar é tão difícil de ser realizada? Como deve ser a avaliação em um ensino inclusivo? $\mathrm{O}$ que é importante para a significativa prática docente inclusiva?

\footnotetext{
${ }^{1}$ Para ter mais informações sobre o histórico das premissas de educação para todos, pode-se consultar a Revista Nova Escola, ed. 139, jan./fev. 2001.
} 
A palavra inclusão traz consigo mudanças e avanços quando é unida à palavra educação. $O$ processo educacional com perspectivas inclusivas é aquele que atende com eficácia todos os alunos, com ou sem deficiências. Por isso é que se diz que a inclusão educacional é perpassada por mudanças, em função de considerar e atender a todos, o que não é possibilitado no processo educacional sem os referenciais inclusivos. Uma definição simples e objetiva para inclusão é a de Mantoan (2006), quando declara que esta é uma possibilidade que se abre para o aprimoramento da educação escolar e para a benfeitoria de todos os alunos com e sem deficiências. Outras definições, todas com a mesma lógica, podem ser encontradas em Sá (2006), Wernech (2006) ou Mrech (2006).

Existem autores que consideram existir diferenças entre os processos representados pelas palavras integração e inclusão, colocando este processo como sendo mais amplo do que aquele. Dentre esses autores, pode-se citar Werneck (2006). Também existem aqueles que consideram as palavras inclusão e integração como representativas do mesmo processo de consideração e participação ativa e significativa de todos no processo educacional. Dentre esses autores, pode-se aqui destacar os seguintes: Lopes e Marquezan (2006), Mattos (2006) e Beyer (2005). Neste trabalho assume-se a postura de considerar as palavras integração e inclusão como próprias de um mesmo sentido, ou seja, aquele em que todos os alunos são considerados e atendidos de maneira eficaz no processo educacional. Nesta perspectiva, dizse não existir diferenças entre integração e inclusão.

A inclusão escolar provoca mudanças de relacionamento entre professores e alunos. Nos ideais inclusivos, o professor não considera seus alunos como quaisquer indivíduos, que encontra em um dado momento da sua vida, mas como pessoas que podem lhe mostrar seus limites profissionais e que lhe possibilitarão ultrapassar esses limites. Na educação inclusiva é de suma importância a cooperação entre todos, o que pode ser desenvolvido com o bom relacionamento entre professores e alunos.

Uma dúvida freqüente quando se fala de educação inclusiva é se esta possibilita mesmo progresso educacional a todos. Mantoan (2006) defende que no processo educacional em que se valorizar as diferenças haverá impulso ao desenvolvimento, isso em função de as diferenças estarem amplamente presentes em todos os momentos educacionais. Prezando-se pela valorização das diferenças se estará possibilitando a participação de todos, o que é imprescindível para o desencadeamento eficaz do processo educacional.

Não são todas as escolas que dão conta de possibilitar as condições necessárias a uma educação inclusiva. Existem escolas que têm estruturas física e pedagógica lineares, rígidas e seletivas, não aceitando com significatividade alunos que não atendam às suas expectativas clássicas. Essas escolas podem ser chamadas de tradicionais. Já existem outras escolas que procuram desenvolver propostas educacionais flexíveis baseadas no que é próprio do seu meio físico, social e cultural, isto é, a partir de estudos das características dos seus alunos, levando em consideração o que estes necessitam e anseiam. Essas escolas, por procurarem conhecer e atender as necessidades dos seus discentes, podem ser chamadas de inclusivas. Mrech (2006) elenca alguns fatores próprios de uma escola inclusiva: colaboração e cooperação entre todos os participantes; boas relações entre professores e alunos; infraestrutura montada de forma acessivel a todos; ampla participação dos pais no processo de ensino-aprendizagem; estabelecimento das estratégias educacionais por todos que participarão do processo educacional (professores, alunos, equipe técnica, pais, entre outros); 
aplicação de estratégias de avaliação que atendam a todos, isto é, que dêem possibilidades de todos os alunos construírem e (re)construírem os conhecimentos; e continuidade de trabalhos voltados à inclusão educacional.

Na educação inclusiva não deve haver a preocupação com apenas os avanços cognitivos dos alunos. É interessante que se compreenda que entre as funções da educação inclusiva estão também a formação e o desenvolvimento das personalidades dos discentes, isto é, de suas capacidades de refletir e agir frente as diversas situações da realidade cotidiana. Seguindo esse raciocínio, Mantoan (2006) defende que o processo educacional inclusivo não deve ser marcado pela lógica de alunos com cabeças bem cheias, mas sim pela lógica de alunos com cabeças bem preparadas.

A inclusão escolar é na atualidade citada pela maioria dos profissionais da educação como sendo difícil de ser realizada na sua totalidade, ou seja, atendendo a todos os alunos. Essa dificuldade torna-se compreensível quando se analisa o modelo pedagógico que esses profissionais trabalham em suas práticas docentes. Fica muito complicado acolher a idéia de desenvolver um ensino inclusivo em uma sala de aula com cadeiras dispostas de forma enfileirada, com um só livro didático sempre aberto com o mesmo objetivo, uma só resposta válida e esperada nas atividades e provas. Para desenvolver a inclusão educacional é necessário que os professores, assim como os demais profissionais da educação, alterem esse modelo, tornando-o flexível e acessível a todos os alunos, com e sem deficiências. Para isso, é de suma importância considerar e valorizar as diferenças.

Outra dúvida freqüente quando se trata do processo educacional inclusivo é referente a como se deve avaliar. Em primeiro lugar é necessário destacar que a avaliação escolar não pode em nenhum momento ser utilizada como um instrumento de poder. Dentro de uma concepção inclusiva deve-se avaliar a aprendizagem através do percurso realizado pelo estudante no decorrer do processo educacional, levando em consideração o que ele é capaz de fazer para ultrapassar as suas dificuldades, para construir seus conhecimentos, tratar informações e participar ativamente da vida escolar e cotidiana.

Por fim, é válido tecer reflexões sobre o que é importante para a significativa prática docente inclusiva. Mantoan (2006) afirma que é necessário recuperar, urgentemente, a confiança dos professores de saberem lidar e desenvolver o processo de ensino-aprendizagem com todos os alunos, sem exceções. Para isso, é oportuno possibilitar aos docentes a participação em cursos que discutam estratégias educacionais visando a participação ativa e consciente de todos os alunos no processo de ensino-aprendizagem. Esses cursos devem atender as necessidades de preparo que os professores têm para desenvolver práticas docentes inclusivas. Como um exemplo, pode-se citar o "Curso de atualização: formação continuada de docentes visando um sistema educativo inclusivo, com ênfase na deficiência visual”, desenvolvido pelo Núcleo de Inclusão do Centro Federal de Educação Tecnológica do Rio Grande do Norte (CEFETRN). Nesse curso, professores das redes públicas de ensino da Cidade do Natal-RN refletiram, de maio a outubro de 2006, com os professores do CEFETRN acerca de métodos e estratégias educacionais para um sistema inclusivo, bem como desenvolveram material didático tátil para o ensino com acessibilidade a todos os alunos, deficientes visuais ou não. 
Em suma, destaca-se a importância da educação inclusiva, constituindo-se em um meio de se trabalhar com a participação e o desenvolvimento de todos os alunos. A seguir, serão realizadas reflexões sobre a educação inclusiva no Brasil, atentando para análises das duas Leis de Diretrizes e Bases da Educação Brasileira, acerca das concepções de inclusão educacional presentes nestas.

\section{Educação inclusiva no Brasil: análises das LDBs (Lei n 4.024/1961 e Lei no 9.394/1996)}

A educação escolar no Brasil é marcada por vários e árduos problemas. Dentre estes, pode-se destacar alguns, como as precariedades de salário e atualização dos professores, as fracas infra-estruturas física e pedagógica existentes nas escolas, o esquecimento, por parte dos docentes, dos alunos com dificuldades e/ou necessidades especiais etc. Esta perspectiva de problemas na educação brasileira é realidade em todo o país, havendo apenas diferenciações de intensidade desses problemas entre as regiões do Brasil.

Diante das precariedades existentes na educação brasileira, faz-se necessário que se pense em um processo que revolucione a atualidade, buscando o melhoramento educacional para todos os que estão envolvidos neste. Para isso, diz-se que é urgente se pensar e trabalhar com o processo educacional inclusivo, que prevê a significatividade para todos os alunos, independentemente das suas diferenças cognitivas, econômicas, culturais, raciais, sociais, dentre outras.

Sendo assim, o objetivo nesta parte do trabalho é refletir sobre o seguinte: no Brasil, há atenções oficiais para a educação inclusiva? Para tentar responder essa indagação é necessário colocar em tela análises das duas LBDs existentes no país, buscando compreender se nessas há ou não atenções para a implantação do processo educacional inclusivo. Essa análise é feita em função de a LDB ser a norma maior que regimenta toda a educação brasileira, trazendo ou não, com isso, os pensamentos educacionais inclusivos para o país.

Vale destacar que o objetivo maior aqui não é o de desencadear aprofundadas análises sobre as LDBs, mas apenas detectar se nessas há ou não atenções para a educação significativa destinada a todos.

No Brasil, até o momento atual, foram promulgadas duas LDBs, uma em 1961 (Lei no 4.024 de 20 de dezembro) e a outra em 1996 (Lei no 9.394 de 20 de dezembro). Cada LDB foi criada em um determinado contexto, trazendo, dessa maneira, algumas diferenças nos objetivos e percursos traçados para a educação brasileira.

A gênese da LDB de 1961 ocorreu em um contexto em que o Estado imprimia uma política populista-desenvolvimentalista, ancorada, principalmente, no capital estrangeiro. $O$ anseio pela criação da LDB foi expresso na Constituição de 1946, que destacava a necessidade de se estabelecer diretrizes e bases para a educação nacional. Essas diretrizes e bases foram trazidas à baila com a LDB de 1961 .

Essa LDB foi estruturada em treze títulos. No Título I foram estabelecidos os objetivos pretendidos na educação brasileira, como: formar cidadãos que compreendam seus direitos e deveres; preparar todos os indivíduos para vencerem nas dificuldades do meio; e condenar 
qualquer tipo de discriminação de classe ou raça. No título II explicitava-se que a educação é direito de todos.

Com isso, vê-se que na LDB de 1961 se objetivava o preparo de "todos os indivíduos" para a vida. Além disso, previa-se a condenação de qualquer tipo de discriminação de classe ou raça na educação. Ratificando esses objetivos, declarou-se ser a educação direito de todos.

Havia também na LDB de 1961 atenções para a educação de alunos com deficiências cognitivas ou físicas, os quais eram chamados na Lei de excepcionais. No Título X desta LDB foi colocado que "a educação dos excepcionais, deve, no que for possível, enquadrar-se no sistema geral de educação, a fim de integrá-los na comunidade”. Dessa maneira, fica mostrado que pretendia-se integrar, na medida do possível, todos os alunos, com deficiências ou não, no processo educacional. Todavia, também no título $\mathrm{X}$ frisava-se que "toda iniciativa privada considerada eficiente pelos conselhos estaduais de educação, e relativa à educação de excepcionais, receberá dos poderes públicos tratamento especial mediante bolsas de estudos, empréstimos e subvenções”. Com isso, ao mesmo tempo em que previa-se a integração de todos os alunos no sistema educacional geral (público), colocava-se também o incentivo à iniciativas privadas que visassem abarcar a educação de alunos com dificuldades. Isso torna contraditórias as afirmações iniciais da LDB, de educação pública para o desenvolvimento de todos, colocando as premissas da educação inclusiva como distantes dos ideais desta Lei.

Já a LDB de 1996 foi criada em um contexto de afirmação da política democrática, tendo como principal fundamento a abertura total do país às especulações externas. Essa LDB segue as premissas da Constituição de 1988, a qual, segundo Cury, Horta e Fávero (2005, p. 22-23), é constituída por "novos temas, velhas posturas; o novo revestido do arcaico; o consagrado enrolado em roupagens atualizadas; tudo isto aparece na confecção dos diferentes capítulos, inclusive no da educação".

A LDB de 1996 é estruturada em nove títulos. No primeiro, destaca-se que a educação deve estar vinculada ao mundo do trabalho e à prática social. Os objetivos para a educação brasileira são explicitados no Título II, sendo destacados aqui os seguintes: igualdade de condições para o acesso e permanência na escola; e pluralismo de idéias e de concepções pedagógicas. Esses objetivos mostram a pretensão de se trabalhar com as diferenças, ou seja, com todos, através da disponibilização de condições para que todos se mantenham na escola e da consideração de várias idéias e concepções pedagógicas.

No Título V, ressalta-se que cabe ao Estado oferecer educação escolar, preferencialmente, na rede regular educacional a todos os alunos, inclusive àqueles com necessidades educacionais especiais. Confirmando isso, ainda no Título V, destaca-se o objetivo do poder público de ampliar o atendimento a todos os alunos na rede pública de ensino.

Sendo assim, pode-se dizer que a LDB de 1996 traz avanços que remetem para a educação de todos. Isso faz com que se tornem cada vez maiores os pensamentos e as atitudes visando a inclusão eficaz de todos os alunos no processo educacional. Não há como negar que na contemporaneidade as discussões e os anseios em torno de uma educação de qualidade para todos são mais intensas, no Brasil, do que em qualquer outro momento histórico. Deve-se prosseguir com essas discussões e com esses anseios, de maneira responsável e comprometida com o desenvolvimento de todos os alunos. Fazendo isso, acredita-se que a educação 
inclusiva possa ser livrada de cair no modismo e, assim, se tornar parte de discursos políticos imediatistas, os quais são alicerçados na intensificação das mazelas sociais.

No desencadear do trabalho, são trazidas, a seguir, percepções de professoras da rede pública de ensino sobre a educação inclusiva. Essas professoras deixam explícitos, através de seus discursos, os desafios encontrados na realidade educacional vigente para se imprimir uma educação que atenda a todos.

\section{Percepções sobre a educação inclusiva}

Após serem realizadas reflexões sobre a definição, o sentido e a consideração legal (em forma de Lei) acerca do processo educacional inclusivo, faz-se imprescindivel conhecer as opiniões docentes sobre esse processo. Conhecer as percepções de professores em relação à inclusão educacional é de suma importância, em função destes serem participantes ativos da educação, conhecendo, assim, seus avanços e suas mazelas. Em outras palavras, diz-se que o entendimento docente sobre o processo aqui discutido é proveitoso para melhor compreensão deste.

Destaca-se que percepção ${ }^{2}$ é aqui entendida como sendo a exteriorização de sentimentos e pensamentos humanos, estando, dessa maneira, inteiramente ligada à subjetividade. Pode-se declarar que a percepção é fortemente egocêntrica. A linha de pensamento sobre percepção seguida neste trabalho é a de Piaget e Inhelder (1993), os quais consideram percepção e cognição como indissociáveis. Com isso, analisando-se as percepções de professores sobre o processo de educação inclusiva pode-se ter conhecimento dos diferentes pontos de vista existentes em relação a este, o que é enriquecedor para as discussões do trabalho em tela.

$\mathrm{Na}$ proposta de trabalho com as percepções docentes, toma-se de empréstimo os depoimentos de professoras da rede pública de ensino de Santa Maria-RS, presentes no trabalho de Duek e Naujorks (2006), intitulado "A inclusão de alunos com necessidades educacionais especiais no ensino regular: o que pensam os professores?”. Nesse trabalho, as autoras trazem as opiniões das professoras ${ }^{3}$ sobre a inclusão educacional, que serão também aqui colocadas em tela.

Contudo, antes de trazer à tona os depoimentos dessas professoras, é necessário efetuar algumas considerações ao trabalho Duek e Naujorks (2006). Essas autoras, assim como outros pensadores, como Bueno (2004), tecem em seu trabalho reflexões reducionistas sobre o processo educacional inclusivo, levando em consideração, com preponderância, a inclusão destinada a alunos deficientes cognitivos e/ou físicos, esquecendo-se de outros alunos que apresentam necessidades educacionais especiais também bastante urgentes, como as sociais, as econômicas, as culturais, as espaciais, dentre outras. Não se pode pensar a inclusão educacional de maneira reduzida, em função desta ser um processo amplo de atendimento impreterível a todos. Para que esse atendimento aconteça de fato, é inevitável pensar esse processo a partir de várias instâncias, como a social, a cognitiva, a econômica, a espacial, a cultural etc.

\footnotetext{
${ }^{2}$ Para obter mais conhecimentos sobre percepção, pode-se consultar o trabalho de Oliveira (2001).

${ }^{3}$ As professoras são chamadas pelas autoras com nomes fictícios, como por exemplo, Hera e Afrodite. Isso é feito para preservar a identidade de cada docente. Esta estratégia será seguida aqui.
} 
A primeira percepção docente em relação à inclusão educacional foi a de que esta é imposta por Leis, não havendo a consideração das opiniões e das situações dos professores no desencadeamento do processo. As professoras deixaram explícito que a inclusão não é proposta a elas, mas sim imposta, o que dificulta o alcance da eficácia do processo: "[...] às vezes, nós não temos nem muita chance de dizer sim ou não [...], nós temos que assumir e assumir" (ATENA citada por DUEK e NAUJORKS, 2006, p. 03); "[...] comecei a trabalhar agora a três anos, quatro anos, com a inclusão [...] não estava claro o que eu tinha que fazer e como eu tinha que fazer [...] o que me angustiou bastante" (DEMÉTER citada por DUEK e NAUJORKS, 2006, p. 03).

Essas declarações mostram que apenas as leis não dão conta do processo de inclusão. É preciso também que haja condições pedagógicas e físicas para que o que é proposto nas leis seja aplicado na realidade, com significatividade. Nisso, Duek e Naujorks (2006) destacam a urgência da formação continuada dos professores, objetivando prepará-los para adequarem suas posturas educacionais frente às diferentes necessidades apresentadas pelos alunos na contemporaneidade educacional. As palavras das autoras deixam claro que além das leis é necessário considerar os contextos, para que a inclusão não seja feita às avessas, tornando-se exclusão:

[...] decretos, embora imprescindíveis, são insuficientes para a concretização do arquétipo inclusivo, pois leis não dão conta de eliminar estereótipos e preconceitos arraigados, podendo, em alguns casos, representar uma inclusão às avessas e dificultar ou, até mesmo, impedir as escolas de avançarem nessa trajetória (DUEK e NAUJORKS, 2006, p. 02).

Algumas das professoras revelaram em suas percepções certa confusão no entendimento do que seja o processo educacional inclusivo. Isso pode ser trazido à baila com as palavras da professora Afrodite (citada por DUEK e NAUJORKS, 2006, p. 03), quando diz:

[...] eu sinto [...] que muitas vezes eu excluo os outros vinte e poucos para incluir ele [o deficiente], então eu acho que não é uma coisa justa. Por isso que, às vezes, eu me questiono com a inclusão, às vezes ela procura fazer o bem, mas ela faz o bem pra poucos em detrimento de vários.

Essa confusão da professora é decorrente da visão reducionista que ela tem em relação à inclusão, acreditando que esse processo é de atendimento apenas aos alunos com deficiências físicas e/ou cognitivas. Essa visão reducionista faz com que ela cite o processo inclusivo como sendo excludente. Frisa-se que se a inclusão for destinada apenas ou principalmente aos alunos deficientes, tornar-se-á realmente excludente. Mais uma vez, destaca-se a necessidade de se pensar a inclusão educacional de maneira ampla, levando em consideração todos os alunos. 
A forma atual como se dá a educação inclusiva é percebida pelas professoras como ineficaz, em função de visar apenas a socialização dos alunos excluídos do sistema. Tendo como principal pilar essa socialização, o processo atual de inclusão é citado como intensificador das exclusões, pois, não basta apenas que os alunos sejam socializados entre si, mas que também atinjam com eficácia desenvolvimentos referentes à intelectualidade, dentre outras dimensões. Com esse raciocínio, Héstia (citada por DUEK e NAUJORKS, 2006, p. 04) apresenta o seguinte discurso: "sabe o que eu vejo? Que estão visando apenas uma socialização, não uma autonomia; [...] isso pra ele, indivíduo, não resulta muito, porque [...] ele se torna mais fora da sociedade ainda [...]”.

Outra percepção das professoras foi a de que existe nos dias atuais grandes contradições entre o que se diz e o que se faz em relação à inclusão. Como já foi destacado neste trabalho, realmente há um fosso entre teoria e prática no processo educacional inclusivo. Muito se pensa e diz e pouco se executa quando se trata desse processo. É necessário e urgente que os discursos inclusivos, marcados, na maioria das vezes, por idéias significativas, sejam levados à prática, pois, só dessa forma pode-se começar a minimizar os graves problemas educacionais existentes em âmbito nacional. É isso que diz a professora Hera (citada por DUEK e NAUJORKS, 2006, p. 04):

acho que esse é o grande problema de todo mundo, de que falar [...] é muito bonito; [...] de repente, alguém lá se dispõe a colocar no papel aquilo que alguém falou. Alguém coloca no papel, só que raros, são muito poucos, aqueles que se disponibilizaram a colocar em prática aquilo que está no papel, aquilo que é falado.

Vale ainda dizer que as professoras não se opõem à inclusão educacional, mas sim acreditam que esta pode revolucionar a educação brasileira, trazendo dias melhores com a participação ativa e consciente de todos. A grande queixa de todas elas é de que o processo inclusivo é pensado e jogado nas escolas de cima para baixo, ou seja, sem que os professores e alunos tenham possibilidades de se preparar para desenvolver com eficácia esse processo. A inclusão educacional não é e nem deve ser entendida como um processo que será executado de maneira igual e linear em todas as escolas. Pelo contrário, para cada contexto há diferentes formas de se buscar e alcançar significatividade educacional para todos os alunos. Cabe a cada professor, juntamente com seus alunos, começar a revolução educacional em sua salade-aula, não esperando que lá de cima venha uma receita mágica que solucione os problemas existentes. Também é necessário exigir dos órgãos educacionais estatais o oferecimento de plenas condições pedagógicas e físicas para que o processo de educação para todos seja desencadeado. Em suma, diz-se que a inclusão deve ser pensada e praticada desde o individual até o coletivo.

Finalmente, cabe retomar algo colocado inicialmente. Para dar sentido prático ao conceito de uma escola efetivamente inclusiva é fundamental avançar na perspectiva de uma escola pública, gratuita, laica e para todos, independentemente de quaisquer diferenciações entre os sujeitos que a ela tenham acesso. Se não for assim, o conceito permanecerá vazio por não encontrar correspondência na realidade concreta. 


\section{Palavras finais}

Para encerrar o trabalho é necessário dizer que pretende-se que as discussões aqui apresentadas sejam motivo para o desencadeamento de outras, seja pela necessidade de aprofundá-las ou de criticá-las. Acredita-se que só assim pode-se fazer com que a ciência não pare de evoluir, tanto do ponto de vista teórico como do social.

Por fim, deixa-se para reflexão o ensinamento de Freire (2002), que declara ser importante no processo de ensino-aprendizagem a existência da convicção de que as mudanças necessárias são plenamente possíveis. Basta que todos os homens desempenhem os seus papéis, sempre tendo como objetivo maior a qualidade educacional para todos.

\section{Referências}

1. BEYER, H. O. O pioneirismo da escola flâmming na proposta de integração (inclusão) escolar na Alemanha: aspectos pedagógicos decorrentes. Revista Educação Especial, Santa Maria: Universidade Federal de Santa Maria, n. 25, p. 9-24, 2005.

2. BUENO, J. G. S. Educação especial brasileira: integração/segregação do aluno diferente. São Paulo: EDUC, 2004.

3. CURY, C. R. J. ; HORTA, J. S. B. ; FÁVERO, O. A relação educação-sociedade-estado pela mediação jurídico-constitucional. In: FÁVERO, O. (org.) A educação nas constituintes brasileiras. Campinas: Autores Associados, 2005.

4. DUEK, V. P. ; NAUJORKS, M. I. A inclusão de alunos com necessidades educacionais especiais no ensino regular: o que pensam os professores? XII Seminário de Pesquisa do CCSA: Universidade, Direitos e Diversidades. Natal: UFRN, ago. 2006.

5. FREIRE, P. Pedagogia da Autonomia: saberes necessários à prática educativa. São Paulo: Paz e Terra, 2002.

6. LOPES, R. P. V. ; MARQUEZAN, R. O envolvimento da família no processo de integração/inclusão do aluno com necessidades especiais. Disponível em: <http://www.pedagobrasil.com.br/educacaoespecial/oenvolvimentodafamilia.htm>. Acesso em: 10 set. 2006.

7. MACEDO, L. Fundamentos para uma educação inclusiva. Disponível em: <http://www.educacaoonline.pro.br/art_fundamentos_para_educacao_inclusiva.asp>. Acesso em: 10 set. 2006.

8. MANTOAN, M. T. E. Uma escola de todos, para todos e com todos: o mote da inclusão. Disponível em: 〈http://www.lite.fae.unicamp.br/papet/2002/nt/ta1.5.htm>. Acesso em: 10 set. 2006.

9. MATTOS, E. A. Deficiente mental: integração / inclusão / exclusão. Disponível em: <http://www.hottopos.com/videtur13/edna.htm>. Acesso em: 10 set. 2006.

10. MRECH, L. M. O que é educação inclusiva? Disponível em: <http://www.geocities.com/Athens/Styx/9231/educacaoinclusiva.html>. Acesso em: 10 set. 2006.

11. OLIVEIRA, L. Ainda sobre a percepção. I Colóquio Nacional de Pós-Graduação em Geografia. A epistemologia da Geografia Contemporânea face aos desafios da sociedade global. Textos básicos relativos aos temas das mesas redondas. Programa de PósGraduação. Mestrado em Geografia. UFPR. nov. 2001. 
12. PIAGET, J. ; INHELDER, B. A representação do espaço na criança. Tradução de Bernardina Machado de Albuquerque. Porto Alegre: Artes Médicas, 1993.

13. PINHEIRO, M. F. O público e o privado na educação: um conflito fora de moda? In: FÁVERO, O. (org.) A educação nas constituintes brasileiras. Campinas: Autores Associados, 2005.

14. REVISTA NOVA ESCOLA. Inclusão: uma longa história em defesa de oportunidades iguais para todos. Ed. 139, jan./fev. 2001.

15. SÁ, E. D. Educação inclusiva no Brasil: sonho ou realidade? Disponível em: <http://intervox.nce.ufrj.br/\%7Eelizabet/palestra.htm>. Acesso em: 10 set. 2006.

16. WERNECK, C. A humanidade como ela é. Disponível em: <http://www.educacional.com.br/entrevistas/entrevista0073.asp>. Acesso em: 10 set. 2006. 